\title{
The Prevalence and Associated Factors of Protein Energy Malnutrition among under Five Year Children in Pediatric OPDs of Public Health Institution in Yirgalem Town, Southern Ethiopia, 2017
}

\author{
Kaleab Tesfaye Tegegne* and lyasu Estiphanos Berisha
}

Health Science, Hawassa Health Science College, Hawassa, Ethiopia

\begin{abstract}
Introduction: Protein energy malnutrition is one of the leading causes of morbidity and mortality in children under the age of five in developing countries. Ethiopia being one of these countries malnutrition is an important public health problem and among the highest in the world

Objectives: The main objective of this study is to assess the prevalence and associated factors of protein energy malnutrition among under-five children in pediatric OPDs of public health institutions at Yirgalem town, Dale woreda, Sidama zone, SNNPR, Ethiopia from September 18-26, 2017.

Methodology: Institutional based cross sectional study was conducted in pediatric OPDs of public health institutions in Yirgalem town, on a total of 204 children age less than five years from September 18-26, 2017. Study subjects were selected by using quota sampling technique. Interviewer administered structured questionnaire and anthropometric measurements were used to collect data. Data was analysed using SPSS version 20.0statistical software.

Result: This study indicated that the prevalence of stunting wasting and Under-weight was $41.2 \%, 1.7 \%$ and $25 \%$ respectively. Factors showed statistically significant association in multivariate analysis were family planning use by mother, children eat together with older siblings and exclusive breast feeding with P-value $(0.02),(0.036)$ and $(0.002)$ respectively.

Conclusion: This study reviled that the prevalence of stunting, wasting and under-weight were higher among under-five children participated in this study. Thus children are at a higher risk of under nutrition related morbidity and mortality. Further progress in under nutrition prevention can be achieved by specifically targeting children at their early age and conducting tailored public education to improve the nutritional status of the study subjects.
\end{abstract}

Keywords: Malnutrition, stunting, wasting, underweight, paediatrics OPD.

\section{INTRODUCTION}

Child malnutrition is one of the measures of health status that the World Health Organization (WHO) recommends for equity in health. According to (WHO) the term malnutrition is the "cellular imbalance between supply of nutrients and energy and body's demand for them to ensure growth, maintenance and specific functions." Stunting, wasting, and underweight are among those. Anthropometric indicators are commonly used to measure malnutrition in a population of underfive children [1].

Children under five year of age are most vulnerable and high risk group, who need special health services. Around $12-15 \%$ of world population is in this age group. $25-30 \%$ of mortality in developing countries occurs in this age group. Malnutrition is a serious problem because it is causing the deaths of 3.5 million children under 5 years old per- year in the world, as well as it is at third level in the world of the disease burden in this age group [2].

*Address correspondence to this author at the Health Science, Hawassa Health Science College, Hawassa, Ethiopia; Tel: +251911066932;

Fax: 0462207884; E-mail: kaleabtesfaye35@gmail.com
More than $25 \%$ under five children in the developing world are malnourished which accounts about 143 million children. Among these 143 million malnourished children, nearly three quarters live in just 10 countries in Sub-Saharan Africa region and more than onequarter of children under five are malnourished (in Nigeria and Ethiopia alone accounts more than 33\%) [3].

Under nutrition, which is focus of this study, conversely has been estimated to be an underlying cause for around half of all child deaths worldwide [2].

In the developing world, one out of every five persons is chronically undernourished and about 200 million children less than five years of age suffer from protein energy malnutrition. Geographically, over twothirds $(72 \%)$ of the world's malnourished children live in Asia (especially South Asia). This figure compares with the $25.6 \%$ found in Africa and only 2.3 in Latin America. An estimated 182 million children under 5 years of age, representing $32.5 \%$ of all preschool children in developing countries, are malnourished when measured in terms of height for age (i.e. stunted). Despite the general worldwide reduction in food insecurity Africa's food security and nutrition security is growing worse [4-6]. 
In Ethiopia, child malnutrition is one of the most serious public health problem and among the highest in the world. This high malnutrition rate in the country poses a significant obstacle for achieving better child health outcomes [7]. According to Ethiopia demographic health survey of 2016 in Ethiopia 38 percent of children under 5 are stunted (below -2 SD), and 18 percent are severely stunted (below -3 SD). Overall, 10 percent of children in Ethiopia are wasted, and 3 percent are severely wasted (below -3 SD). The results show that 24 percent of all children are underweight (below -2 SD), and 7 percent are severely underweight (below $-3 \mathrm{SD}$ ).

According to the same report in SNNPR 38.6 percent of children under 5 are considered short for their age or stunted (below -2 SD), and 20.2 percent are severely stunted (below $-3 \mathrm{SD}$ ). Overall, 6 percent of children in SNNPR are wasted, and 1.7 percent are severely wasted (below $-3 \mathrm{SD}$ ). The results show that 21.1percent of all children are underweight (below -2 SD), and 6.7 percent are severely underweight (below $3 \mathrm{SD})$ [8].

\section{SUBJECTS AND METHODS}

\subsection{Study Area and Period}

This study was conducted in public health facilities found in Yirgalem town by using institutional based cross sectional study design. Yirgalem town is one of the two city administration in Sidama zone and also capital city of Dale woreda. The study area is $47 \mathrm{~km}$ south of Hawassa, the regional capital of the south region and $317 \mathrm{~km}$ south of the capital, Addis Ababa along Addis Ababa-Moyale high way study design.

Institutional based cross sectional study design was conducted in public health institutions found in Yirgalem town, SNNPR region on a total of 204 underfive year children from September 18 -26, 2017.

\subsection{Study Population}

All Children less than 5 years of age who visited pediatric OPDs of public health institutions in Yirgalem town during the study period.

\subsection{Inclusion and Exclusion Criteria}

\subsubsection{Inclusion}

Children under five years of age who brought to pediatric OPD of public health institutions of Yirgalem town during the study period were included in the study.

\subsubsection{Exclusion Criteria}

Critically sick and grossly deformed child

Mothers or care givers who were not willing to give required information

\subsection{Sample size and Sampling technique}

The sample size was determined by using single population proportion formula by the fallowing assumption for prevalence of under-weight as $20.5 \%$ in Wonsho woreda, Sidama zone, southern Ethiopia [9], desired precision (d) as $5 \%$ and $95 \%$ as confidence interval.

Therefore sample size is calculated as;

$n=\frac{(z-a / 2) 2(p)(1-p)}{d^{2}}$

Where

$\mathrm{n}=$ sample size

$\mathrm{P}=$ proportion

$d=$ margin of error

$z=$ standard normal curve of respective confidence interval

$n=\frac{(1.96) 2(0.205)(1-0.205)}{(0.05) 2}=250$

Population correction formula was required since the average monthly patient flow of paediatrics OPDs in public health institutions (924) was less than 10,000.

$\mathrm{nf}=\mathrm{ni} /[1+\mathrm{ni} / \mathrm{N}]=251 /[1+251 / 924]=197$

Where

$\mathrm{nf}=$ final sample size after correction

$\mathrm{ni}=$ initial sample size before correction

$\mathrm{N}=$ Number of children visiting paediatrics OPD per month

Considering a $10 \%$ non-respondent rate the required sample was become $197+197 \times 10 \%=$ $197+20=217$. Therefore the final sample size was 217 .

Study subjects were selected from public health institutions found at Yirgalem town by using quota sampling technique. The calculated sample size (217) 
was proportionally allocated among the health institutions based on their patient flow experience (135 for hospital and 82 for the health center). All children under 5 year of age who visited the paediatrics OPD of the health institutions during the study period and fulfil the inclusion criteria were selected as study subjects consecutively until the calculated sample size was attained.

\subsection{Data Collection Procedures}

Interviewer administered structured questionnaire adapted from different literature was used to collect socio demographic and other variables. The first questionnaire was prepared in English then translated to Amharic for field work purpose and back to English for checking language consistency. Then the questionnaire was pretested on $5 \%$ mothers or care givers in under-five OPD of Halaba health canter before three days of actual data collection to see the consistency of contents of the instrument; then correction and modification was done on the gap identified during interview.

Anthropometric measurement equipment's such as weighing Scales, Length/height board and MUAC tape were obtained from respective health institutions and used. Both data collection and supervision was undertaken by five members of principal investigators, who partially completed their post-basic education on public health. Two data collectors were assigned to each under-five year OPD (one interview the mother or care giver and fill the questionnaire while the other was taking anthropometric measurements). The data collection was conducted in private rooms to ensure confidentiality.

\subsection{Data Quality Assurance}

The data quality was maintained by clearly informing the data collectors' about how to fill the questionnaires and how to take the anthropometric measurements. During data collection and at the end of each day, regular follow up was under taken and the way of filling the questionnaires was reviewed and checked for completeness, accuracy and consistency.

Weighing scales were calibrated with known weight object regularly. The scales indicators were checked against zero reading before weighing every child and the measurement was approximated to the nearest 100 gram. Children were weighed with minimum/light/ clothing and no shoes. Length was measured in recombinant position using sliding board by two data collectors for children age up to 23 months, However height of children 24 months and above was measured using a vertical wooden height board by placing the child on the measuring board, and child standing upright in the middle of the board. The child's head, shoulders, buttocks and heels touching the board and the readings were taken to the nearest $1 \mathrm{~mm}$.

\subsection{Data Processing and Analysis}

SPSS version 20.0 statistical software was used for data analysis. National \& WHO standards was utilized to convert height and weight measurements into Zscores of the $\mathrm{H} / \mathrm{A}, \mathrm{W} / \mathrm{H}$ and W/A indices considering age and sex of the children. Bivariate and multivariate logistic regression analysis was used to identify determinants of nutritional status and to account for potential confounding factors. Statistical association was declared significant if $p$-value is less than 0.05 .

\subsection{Operational Definition}

Anthropometry: Is the measurement of the variation of physical dimensions of the human body at different age levels which is used to assess the nutritional status of individuals and population groups

Colostrum depletion: Emptying the first and thickest portion of the breast milk before initiating breast feeding to the new born.

Complimentary food: Foods which are required by the child, at six months of age, in addition to sustained breast feeding.

Diarrhoea: a child having three or more loose or watery stools per day.

Fever: A child with elevated body temperature than normal.

Income: periodic monthly earning from one's business, lands, work, investment, etc.

Latrine condition: The presence or absence of latrine in the household.

Meal pattern: is a set of food components, food items and minimum quantities required for a breakfast, snack, or lunch or supper for specific age group of children

Method of feeding: Utensils used by the mother or care giver for feeing of complimentary food to the children. 
PEM: A child was labelled to have PEM if any of the nutritional assessment indices, Wt/age, Ht/age and $\mathrm{Wt} / \mathrm{Ht}$ is less than normal (Z-score less than -2SDof WHO reference population)

Prelacteal feeding: Any food except breast milk provided to a child before initiating breast feeding

Stunting: height-for-age Z-score less than $<-2$ SD, from the median of $\mathrm{NCHS} / \mathrm{WHO}$ reference population.

Underweight: Weight-for-age Z-score less than 2SD, from the median of NCHS/WHO reference population.

Wasting: Weight -for- height Z-score below 2SDfrom the NCHS/WHO median value

\subsection{Ethical Considerations}

Ethical clearance was obtained from Ethical Review Committee of Hawassa College of Health Sciences. Then officials at different levels in the study area were communicated through letters from the College. Written informed consent was taken from each respondent prior to the interview after the purpose of the study was explained to them. Confidentiality of the information was assured and privacy of the respondents' was maintained. Children's found to have severe malnutrition was linked to inpatient or out-patient therapeutic feeding programs

\section{RESULTS}

3.1. Socio- Economic and Demographic Characteristics of the Children Involved in the Study

A total of 204 children age $<5$ years from pediatric OPDs of public health institutions in Yirgalem town took part in this study (which is $94 \%$ response rate). From which $96(47.1 \%)$ of children were male and the rest $108(52.9 \%)$ were female. The average age of the children was 22 months $(S D \pm 13.4)$ and the average size of the family was 5 ( $S D \pm 1.48$ ).

The average ages of mothers were 22 years with \pm 13.4 SD. Majority (75\%) of the mothers were housewives and $45.1 \%$ of the fathers were farmers. $40.7 \%$ of the mothers were illiterate and 33.3 attended only first cycle education (see Figure 1). The mean monthly income of the household was 1749 birr with \pm 1467 SD. When we see the study participants $68.6 \%$ of were Sidama in ethnicity and were protestant
Christianity followers. Majority of the study participants were residing in rural areas.

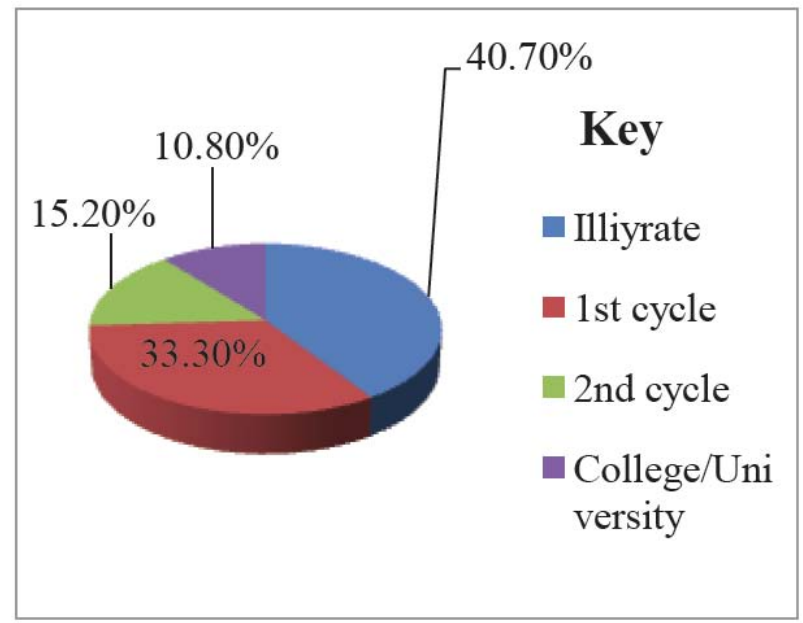

Figure 1: Educational status of the mothers' of children involved in the study at public health institutions of Yirgalem, September, 2017

\subsection{Behavioral and Environmental Characteristics of the Parents of the Children}

From the study participants $92.2 \%$ have latrine and majority $(96 \%)$ mothers/care givers wash their hand before feeding their child. 57(27.9\%) children eat together with older siblings from which $39(68.4 \%)$ were stunted and $15(26.3 \%)$ were wasted. Mothers who not use any type of family planning method were $55(27 \%)$ and $11(20 \%)$ children whose mother was not using FP were wasted and 48(87.3\%) were stunted. 96(47.1) mothers responded to use bottle to give complimentary food to their child. Among those who used bottles $15(15.6 \%)$ children were wasted and $50(52 \%)$ were stunted.

\subsection{Child Health and Caring Practices}

Regarding the presenting illness, majority (33.4\%) of the children participated in our study were presented with the complaint of fever followed by diarrhoea (28.9\%) and cough (25\%). Among children presented with diarrhoea more than half $(51 \%)$ were found to have PEM. $37.8 \%$ of children with fever and $37.2 \%$ of children presented with cough were also found to have PEM.

Children who had at least one episode of diarrhoea within the last two weeks of the study were $63(30.9 \%)$ from which $57.1 \%, 30.1 \%$ and $50.7 \%$ found to be stunted, wasted and underweight respectively. Only $33.8 \%$ of children were received medication for intestinal worms. 
Table 1: Socio-Economic and Demographic Characteristics of Study Participants at Public Health Institutions of Yirgalem September, 2017, n=204

\begin{tabular}{|c|c|c|c|}
\hline Variable & Category & Frequency & Percent \\
\hline \multirow[t]{2}{*}{ Sex of the children } & Male & 96 & 47.1 \\
\hline & Female & 108 & 52.9 \\
\hline \multirow[t]{4}{*}{ Age of the children } & $<12$ months & 59 & 28.9 \\
\hline & $12-23$ months & 68 & 33.3 \\
\hline & 24-35 months & 37 & 18.1 \\
\hline & $48-59$ months & 18 & 8.8 \\
\hline \multirow[t]{4}{*}{ Fathers occupation } & Farmer & 92 & 45.1 \\
\hline & Employee & 59 & 28.9 \\
\hline & Merchant & 35 & 17.2 \\
\hline & Other & 18 & 8.8 \\
\hline \multirow[t]{2}{*}{ Residence } & Rural & 108 & 52.9 \\
\hline & Urban & 96 & 46.6 \\
\hline \multirow[t]{3}{*}{ Religion } & Protestant & 126 & 61.8 \\
\hline & Orthodox & 60 & 29.4 \\
\hline & Muslim & 18 & 8.8 \\
\hline
\end{tabular}

Table 2: Behavioural and Environmental Characteristics of the Study Participants at Public Health Institutions of Yirgalem Town September, 2017, $\mathrm{n}=204$

\begin{tabular}{|c|c|c|c|}
\hline Wash hand before child feeding & Yes & 196 & 96.1 \\
\hline \multirow[t]{2}{*}{ Child eat together with older siblings } & Yes & 57 & 27.9 \\
\hline & No & 147 & 72.1 \\
\hline \multirow[t]{2}{*}{ Give other food before breast feeding } & Yes & 30 & 14.7 \\
\hline & No & 173 & 84.8 \\
\hline \multirow[t]{2}{*}{ What is used to give complimentary food to the child } & Bottle & 96 & 47.1 \\
\hline & Spoon & 39 & 19.1 \\
\hline Duration of exclusive breast feeding & $\geq 6$ months & 98 & 48 \\
\hline \multirow[t]{2}{*}{ Latrine } & Yes & 188 & 92.2 \\
\hline & No & 16 & 78 \\
\hline \multirow[t]{4}{*}{ Water source of the family } & Pipe water & 56 & 27.5 \\
\hline & protected well & 116 & 59.6 \\
\hline & Unprotected well & 20 & 9.8 \\
\hline & Spring & 12 & 5.9 \\
\hline
\end{tabular}




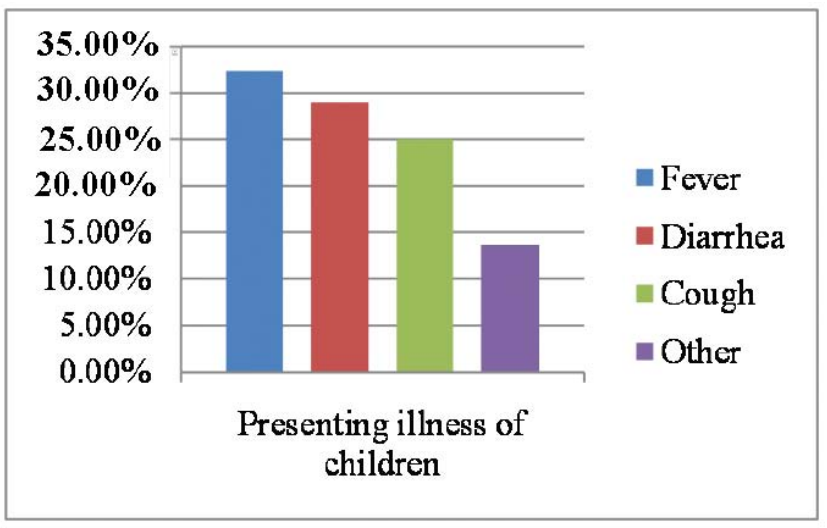

Figure 2: Presenting illness of children in paediatrics OPDs of public health institutions of Yirgalem town September, 2017.

Table 3: Health Condition of Children Participated in this Study at Public Health Institutions of Yirgalem Town September, 2017, n =204

\begin{tabular}{|c|c|c|c|}
\hline Variable & Category & Frequency & Percent \\
\hline \hline Presenting illness & Fever & 66 & 32.4 \\
\cline { 2 - 4 } & Diarrhoea & 59 & 28.9 \\
\cline { 2 - 4 } & Cough & 51 & 25 \\
\cline { 2 - 4 } & Other & 28 & \\
\hline \multirow{2}{*}{$\begin{array}{c}\text { Diarrhoea in the } \\
\text { last two weeks }\end{array}$} & Yes & 63 & 30.9 \\
\cline { 2 - 4 } & No & 14.1 & 69.1 \\
\hline $\begin{array}{c}\text { Deworming in the } \\
\text { last 6 months }\end{array}$ & Yes & 69 & 33.8 \\
\cline { 2 - 4 } & No & 135 & 66.2 \\
\hline
\end{tabular}

\subsection{Nutritional Status of the Children}

According to our study the prevalence of stunting $(\mathrm{Ht} /$ Age below -2 SD) among children visiting underfive OPDs of public health institutions at Yirgalem town was $41.2 \%$ of this $20.1 \%$ were severely stunted (below $-3 \mathrm{SD}) .12 .7 \%$ of children were wasted $(\mathrm{Wt} / \mathrm{Ht}$ below -2 SD), from which $6.9 \%$ were severely wasted (below -3 SD). Underweight prevalence was $25 \%$ and from this $11.8 \%$ were found to be severely underweight (Wt/age below -3 SD). Almost all (96\%) wasted children were also found to have stunting. $13.2 \%$ of children were found to be MUAC < $12.5 \mathrm{~cm}$ from which 6.4 were MUAC $<11 \mathrm{~cm}$ and $6(2.9 \%)$ children found to have oedema.

\subsection{The Prevalence of PEM in Relation to Associated Factors}

When we see the age distribution of PEM among study participants, the prevalence of stunting and wasting were higher among age groups between one to two years of age but the prevalence of wasting is higher in children age less than one year (see Figure 4).

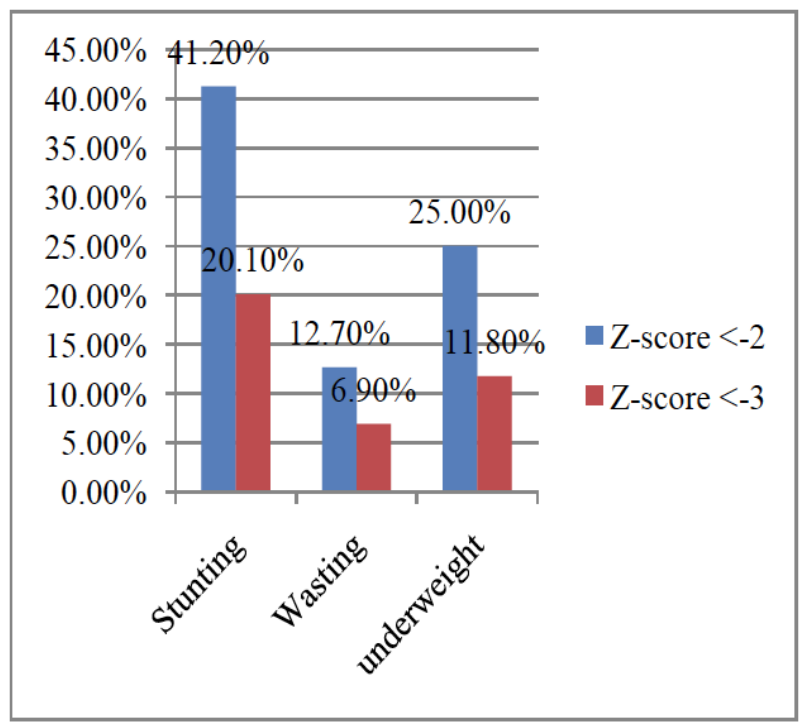

Figure 3: Prevalence of different forms of PEM among children participated in this study in public health institutions of Yirgalem town, South Ethiopia, September, 2017.

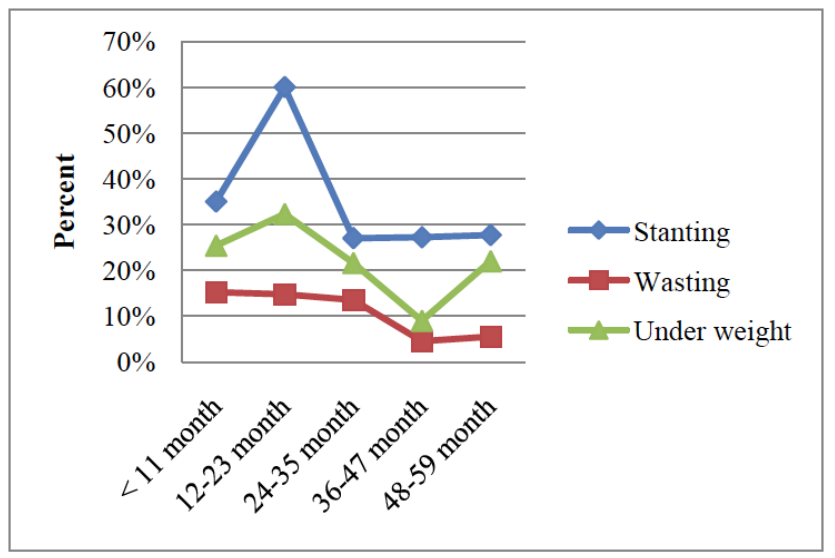

Figure 4: Age distribution of various forms of PEM in children participated in this study in public health institutions of Yirgalem town, South Ethiopia, September, 2017.

The prevalence of PEM in children whose mother was literate is markedly lower compared to illiterate mothers, which is $33 \%$ and $56 \%$ respectively. Compared to urban residents the prevalence of PEM is higher in rural residents, which is $35 \%$ and $49 \%$ respectively. This study also reviled an increased prevalence of PEM among children used bottle for complimentary feeding (92\%) compared to children not used bottle. The prevalence of PEM in children who fed breast milk exclusively for six month and above was $34 \%$ which is lower compared to children started 
complimentary feeding before six months which was $93 \%$. The prevalence of PEM among children given other food before breast milk was $66 \%$ which is high compared to the prevalence in children not given other food prior to breast milk (45\%). The prevalence of PEM among children eat together with older siblings was $70 \%$ which is very high compared to children not eat together with older siblings (32\%). The prevalence of PEM among children who had at list one episode of diarrhoea in the last two weeks of study was $60 \%$ which is very high compared to children not had any episode of diarrhoea (35\%).

\subsection{Factors Associated with Protein Energy Malnutrition}

In order to investigate the association of independent variables with protein energy malnutrition, both bivariate and multivariate logistic regression analysis were used. Those variables showed association with outcome variables at $p$-value of less than or equal to 0.05 in the bivariate analysis were selected as candidate variables for multivariate logistic regression analysis

\subsection{Results of Multivariate Logistic Regression Analysis}

The multivariate logistic regression analysis was used by taking all factors that showed association in bivariate logistic regression into account simultaneously. Eight independent variables showed association in bivariate logistic regression and only three contributing factors such as child eating with older siblings, mother not using family planning and exclusive breast feeding remained to be significantly and independently associated with protein energy malnutrition.

Those children whose mother not use family planning were 2.5 times more likely to have protein energy malnutrition as compared to those children whose mother use family planning with $[A O R=2.55$, $95 \% \mathrm{Cl}(1.16,5.58)]$ (P-value $=0.02)$. Children eat together with older siblings showed statistically significant association with outcome variable. Those children who eat together with older siblings were 2.4 times more likely to have protein energy malnutrition as compared to those children who does not eat together

Table 4: Variables Shoed Association in Bivariate Logistic Regression=204

\begin{tabular}{|c|c|c|c|c|c|}
\hline \multirow{2}{*}{ S. No } & \multirow{2}{*}{ Variables } & \multirow{2}{*}{ P. value } & \multirow{2}{*}{ COR } & \multicolumn{2}{|c|}{$95 \%$ confidence interval } \\
\hline & & & & Lower & Upper \\
\hline 1 & Family Size $\geq 5$ & 0.003 & 0.413 & 0.231 & 0.739 \\
\hline 2 & Educational status of the Mother & 0.001 & 0.378 & 0.213 & 0.673 \\
\hline 3 & Absence of latrine & 0.036 & 0.308 & 0.103 & 0.923 \\
\hline 4 & Child eating With older Siblings & 0.000 & 0.200 & 0.103 & 0.388 \\
\hline 5 & Mother not use FP & 0.000 & 0.246 & 0.127 & 0.476 \\
\hline 6 & Exclusive BF for less than 6 months & 0.000 & 0.037 & 0.008 & 0.159 \\
\hline 7 & Giving other Food Before BF & 0.005 & 0.313 & 0.138 & 0.710 \\
\hline 8 & Diarrhoea in the last two weeks & 0.001 & 0.350 & 0.190 & 0.646 \\
\hline
\end{tabular}

Table 5: Result for Multivariate Logistic Regression Analysis, $\mathbf{n}=204$

\begin{tabular}{|c|c|c|c|c|}
\hline \multirow{2}{*}{ Variable entered } & \multicolumn{2}{|c|}{ P.V } & AOR & 95\% C.I. for EXP(B) \\
\cline { 2 - 5 } & \multicolumn{2}{|c|}{} & 1.393 & .697 \\
\hline Family Size $\geq 5$ & .348 & 1.731 & .865 & 2.783 \\
\hline Educational status of the Mother & .121 & 1.574 & .410 & 3.465 \\
\hline Absence of latrine & .509 & 2.376 & 1.058 & 6.049 \\
\hline Child eating With older Siblings & .036 & 2.546 & 1.160 & 5.334 \\
\hline Mother not use FP & .020 & 5.275 & 3.161 & .614 \\
\hline Exclusive BF for less than 6 months & .002 & 1.772 & .363 & 20.083 \\
\hline Giving other Food Before BF & .290 & .787 & 5.117 \\
\hline Diarrhoea in the last two weeks & .545 & & & 1.707 \\
\hline
\end{tabular}


with older siblings with $[\mathrm{AOR}=5.33,95 \% \mathrm{Cl}(1.06,5.33)]$ (p-value 0.036 ). Duration of exclusive breast feeding was showed statistically significant association with protein energy malnutrition. Children who did not exclusively fed breast milk for at least six months were 5 times more likely to have protein energy malnutrition as compared to those children who exclusively fed breast milk for six months and above with $[\mathrm{AOR}=5.27$, $95 \% \mathrm{Cl}(3.16,20.08)]$ ( $p$-value $=0.002)$.

\section{DISCUSSION AND CONCLUSION}

As this study showed, the prevalence of stunting, wasting and under- weight was $41.6 \%, 12.7 \%$ and $25 \%$ respectively which is much higher compared to Ethiopia demographic health survey report of 2016 which reported $38 \%$ stunting $10 \%$ of wasting and $24 \%$ underweight [8]. The prevalence of wasting and underweight was also higher compared to community based cross sectional study conducted at Haramaya district which observed $10.7 \%$ wasting and $21 \%$ under-weight, respect [10]. When we see the study done at Amhara Regional State, the prevalence of stunting and underweight were found to be $52 \%$, and $33.4 \%$, respectively which is much higher compared to our result [11]. This might be due to difference in study design and study area.

According to this study PEM was more common in children age less than two years (73\%), compared to 25 years age group (54\%), but the association between age and PEM was not statistically significant. This finding is contradicting with study done in Bangladesh, which found-out an increased risk of malnutrition as the age of the child increases [12]. This might be due to difference in study design.

Duration of exclusive breast feeding was showed statistically significant association with protein energy malnutrition. Children who feedbreast milk exclusively for less than six months were 5 times more likely to have protein energy malnutrition as compared to those children who exclusively fed breast milk for six months and above with $[A O R=5.27,95 \% \mathrm{Cl}(3.16,20.08)$ ] ( $p$ value $=0.002$ ). Similar study conducted in India was also showed statistically significant association between exclusive breast feeding and PEM with (p.v=0.007) [13].

As shown in the result of this study, those children whose mother not use family planning were 2.5 times more likely to have protein energy malnutrition as compared to those children whose mother use family planning with $[\mathrm{AOR}=2.55,95 \% \mathrm{Cl}(1.16,5.58)](\mathrm{P}-$ value $=0.02$ ). This finding is in consistent with study conducted in Northern Shewa, Oromia Region [14].

Children eat together with older siblings showed statistically significant association with outcome variable. Those children who eat together with older siblings were 2.4 times more likely to have protein energy malnutrition as compared to those children who does not eat together with older siblings with $[A O R=5.02,95 \% \mathrm{Cl}(1.06,5.33)]$ ( $p$-value 0.036). This finding is in consistent with similar study conducted in India which observed statistically significant associating with (p.v 0.003) [13].

The prevalence of PEM among children whose mother was literate is markedly lower compared to children of illiterate mothers, which is $33 \%$ and $56 \%$ respectively. But statistically significant association was not observed. This finding is consistent with similar study done in Bangladesh [12]. This is because educated mothers are more conscious about their children's health; and they tend to look after their children in better way [14].

This study revealed that place of residence makes a great difference in the prevalence of PEM. Compared to urban residents the prevalence of PEM was higher in rural residents, which was $35 \%$ and $49 \%$ respectively which is consistent with study conducted in Zambia [15].

The prevalence of PEM among children how had at list one episode of diarrhea in the last two weeks was $60 \%$ which is very high compared to children not had any episode of diarrhoea( $35 \%)$. This might be because diarrhea causes dehydration and loss of appetite which is followed by decreased food intake and then malnutrition. And this finding was in agreement with the study conducted in North Gondar and Machakal woreda Northwest Ethiopia [16, 17].

This study revealed that the prevalence of stunting, wasting and under-weight were higher among under five children at paediatrics OPDs of public health institutions of Yirgalem town. Thus children are at a higher risk of under nutrition related morbidity and mortality. The prevalence statistics in this study were higher than the regional and national figures of Ethiopia Demographic health survey 2016 national report. According to investigation of association of independent variables with dependent variable in multivariate analysis, eating with older siblings, family 
planning use by mothers and exclusive breast feeding showed a significant association with dependent variable. Further progress in under nutrition prevention can be achieved by specifically targeting children at their early age and conducting tailored public education to improve the nutritional status of the study subjects.

\section{ACKNOWLEDGEMENT}

We would like to acknowledge Hawassa College of health sciences for the well-equipped library with different reference books and access of internet services that we used for proposal and final paper writing. We would also like to thank the college for financial support.

Our thanks go to Yirgalem general hospital and Yirgalem health center for unreserved cooperation and supporting us with anthropometric tools during data collection.

We are glad to thank the mothers and care givers of children who participated in this study and took their time to provide us information.

\section{REFERENCES}

[1] WHO. Global strategy for infant and young child feeding. WHA 55/15, April 2002.

[2] National family health survey (NFHS-3) 2005-06, India. Suggested citation: International Institute for Population Sciences (IIPS) and Macro International 2009; 1: 269.

[3] UNICEF. Children and the Millennium Development Goals. Progress for children a report card on nutrition 2007.

[4] Consultancy Africa Inteligence. Food insecurity and malnutrition in Africa, 2012. public.health@consultancyafrica. com accessed on 29 May 2013.

[5] WHO. Household Food and Nutrition Security, 2001. www.who.int accessed on 30 May 2013.

[6] Consultancy Africa Intelligence. Food Sovereignty, 2008. www.consultancyafriaca.com accessed on 30 May 2013.
[7] Eticha K. Prevalence and Determinants of Child Malnutrition In Gimbi district. Addis ababa university 2013; [master thesis].

[8] Ethiopian Central statistical Agency. Ethiopian Demographic and Health Survey. ICF International Calverton: Maryland 2016.

[9] Gamecha R, Demses T, Admise A. The magnitude of nutritional under-weight and associated factors among children aged 6-59 months in Wonsho woreda, Sidama zone southern Ethiopia February 07, 2017. https://doi.org/10.2174/1874944501610010007

[10] Sisay Z. magnitude and factors associated with malnutrition of children under -five years of age in rural kebeles of Haramaya, Ethiopia Harar bull Health sci Extracts Number $2011 ; 2012$.

[11] FMOH. Health sector development programme IV First Year annual performance report, Ethiopia, EFY (2013).

[12] Mostefa KS. Socio economic determinants of sever and moderate stunting among under-five children of rural Bangladesh. Malaysian Journal of Nutrition 2011; 17: 105118 ,

[13] Tiwari SR, Bandi JR, Awasthi SR, Sharma AK. Assessment of prevalence of protein energy malnutrition inunder 5 year children in an urban slum of Mumbai, India and to study associated factors. Int J Community Med Public Health 2016; 3: 1129-34. https://doi.org/10.18203/2394-6040.ijcmph20161371

[14] Mengistu K, Alemu K, Destaw B. Prevalence of malnutrition and associated factors among children aged 6-59 months at Hidabu District, Northern Shewa, Oromia Regional state 2013.

https://doi.org/10.4172/2161-0509-3-T1-001

[15] Nzala SH, Siziya S, Babaniyi O, Songolo P, Muula AS, Rudatikira E. demographic Cultural and environmental factors associated with frequency and severity of malnutrition among Zambian childrenless than five years of age. J public health Epidemiol 2011; 3(8): 362-70.

[16] Bantamen G, Belaynew W, Dube J. Assessment of factors associated with malnutrition among under five years age children at Machakel Woreda, Northwest Ethiopia: a case control study. J Nutr Food Sci 2014; 4: 256. doi:10. 4172/2155-9600.1000256

[17] Amsalu S, Tigabu Z. Risk factors for severe acute malnutrition in children under the age of five: a case control study. Ethiop J Health Dev 2008; 22: 21 https://doi.org/10.4314/ejhd.v22i1.10058 